\title{
DANCE OF BEAUTY BETWEEN LIVING AND NONLIVING - EXHIBITION CATALOGUE PERFECTION OF EVOLUTION - REVELATION
}

\section{VlatKa MičEtić Stanković}

Croatian Natural History Museum, Demetrova 1, HR-10000 Zagreb (e-mail: vlatkams@hpm.hr)

In the Croatian Natural History Museum on March 17 ${ }^{\text {th }}, 2017$ the exhibition catalogue „Perfection of Evolution - Revelation“ was presented to the museum's visitors and nature lovers. The authors of the catalogue are museum employees and enthusiasts, Nives Borčić, Petar Crnčan, Iva Mihoci, Ph. D. and Ivan Razum (Fig. 1). It is a catalogue of the exhibition that was held in 2016 in our museum on the occasion of the celebration of the $30^{\text {th }}$ anniversary of the unification of three museums: the Croatian National Museum of Zoology, the Museum of Mineralogy and Petrography, and the Museum of Geology and Palaeontology. During the exhibition the visitors had the opportunity, for the first time ever, to get acquainted with one of the most valuable and priceless collections from our museum holdings. This is the collection that was created by the knowledge, passion and love of one of the greatest entomologists ever, René Mikšić. The collection encompasses 12,000 museum objects of beetles (Coleoptera), mainly representatives of the families Scarabaeidae, Lucanidae, Cerambycidae and Lampyridae, mostly collected in exotic Oriental region. Additionally, Mikšić described more than 230 taxa, 120 type series of which are held in the collection with great care.

In the exhibition, beetles were presented together with minerals and rocks that correspond in their beauty, structures, colours, reflections, and scientific importance. Nives Borčić, the lead author of the catalogue, during her involvement in the realization of the exhibition fell in love with the beauty and the harmony of the animate and inanimate. This resulted in a catalogue that was made in cooperation with other collaborators on the exhibition, primarily with Petar Crnčan. It is certainly not an ordinary museological

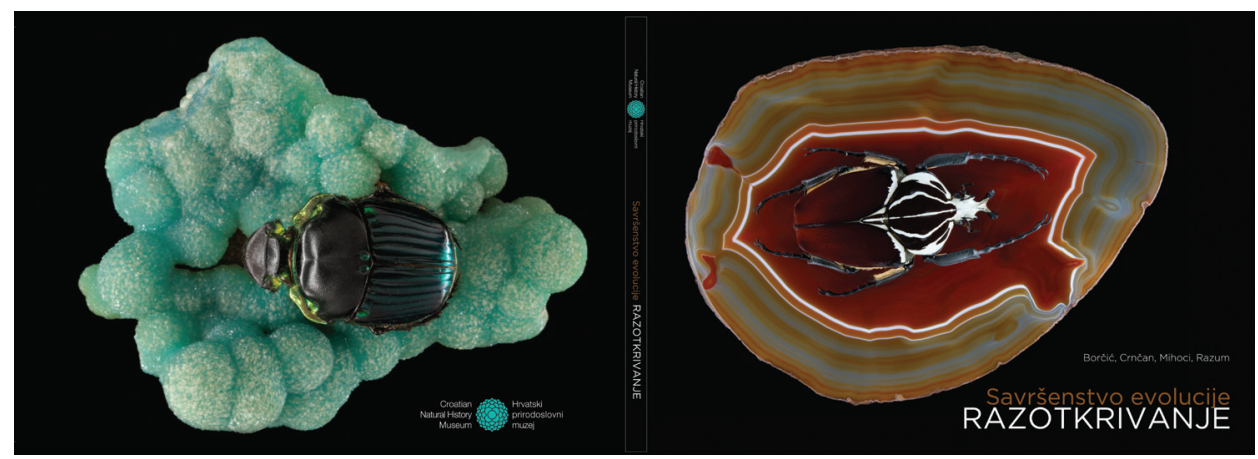

Fig. 1. Catalogue „Perfection of Evolution - Revelation” 


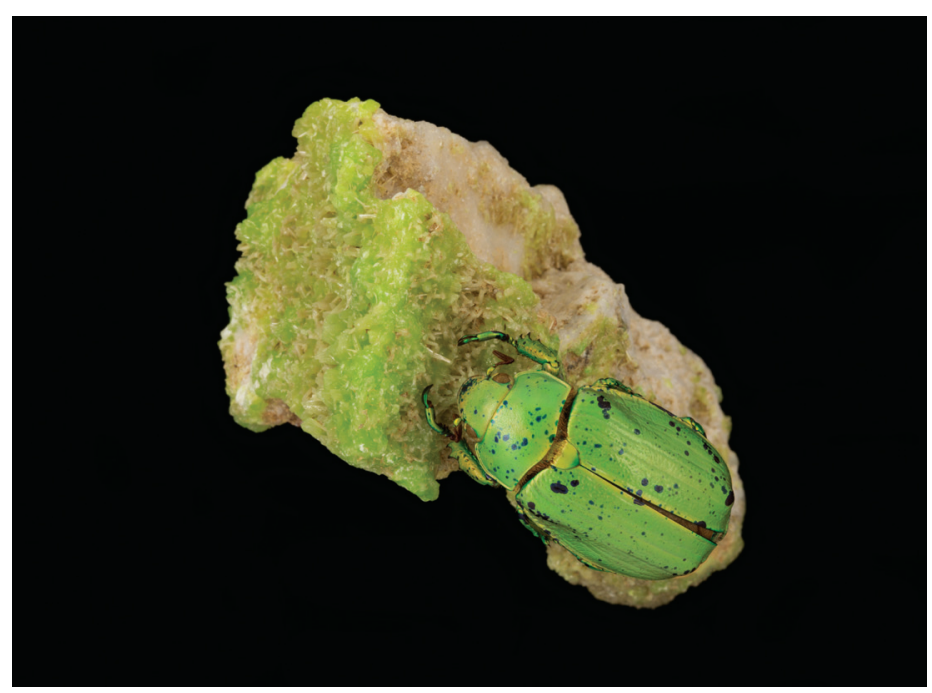

Fig. 2. Chrysina laniventris (Sturm, 1843), Mexico - Pyromorphite, Ingurtosu, Italy

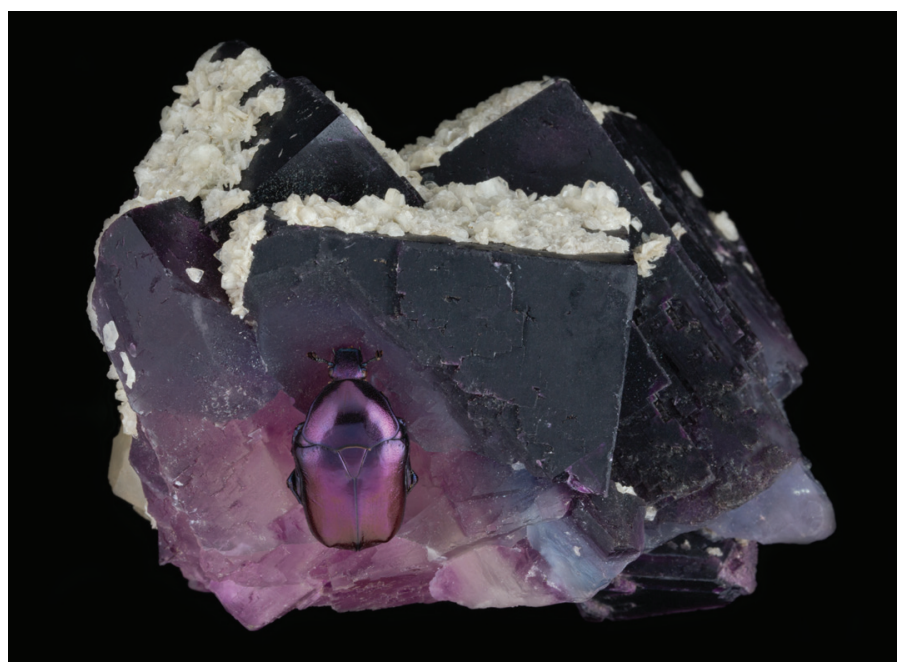

Fig. 3. Protaetia (Eupotosia) mirifica koenigi (Reitter, 1894), Akbes, Syria - Fluorite, Barite, Calcite, Illinois, USA

catalogue, but really a work of art that will evoke a sense of wonder in every reader (Fig. 2). Nikša Martinac did the visual design, which is completely dedicated to highlighting the beauty of the photographed museum objects (Fig. 3). Iva Mihoci, Ph.D. and Ivan Razum concisely explained the importance of the museum objects photographed. The same authors also gave a list of the photographed museum objects that follows recent nomenclature, with their sampling sites. The catalogue thus represents a whole that has both artistic and scientific value. It is a unique example of the way in which an exhibition can be perpetuated, an epitome of the knowledge, the playfulness and inspiration of 


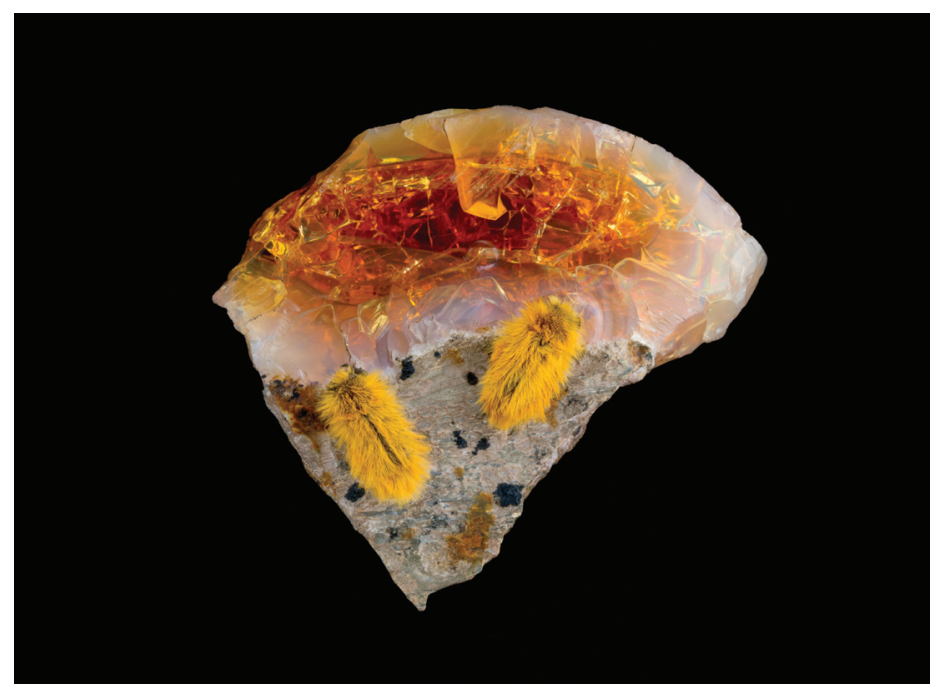

Fig. 4. Pygopleurus vulpes (Fabricius, 1781), Gaza - Pčinja - opal - fire opal, Mexico

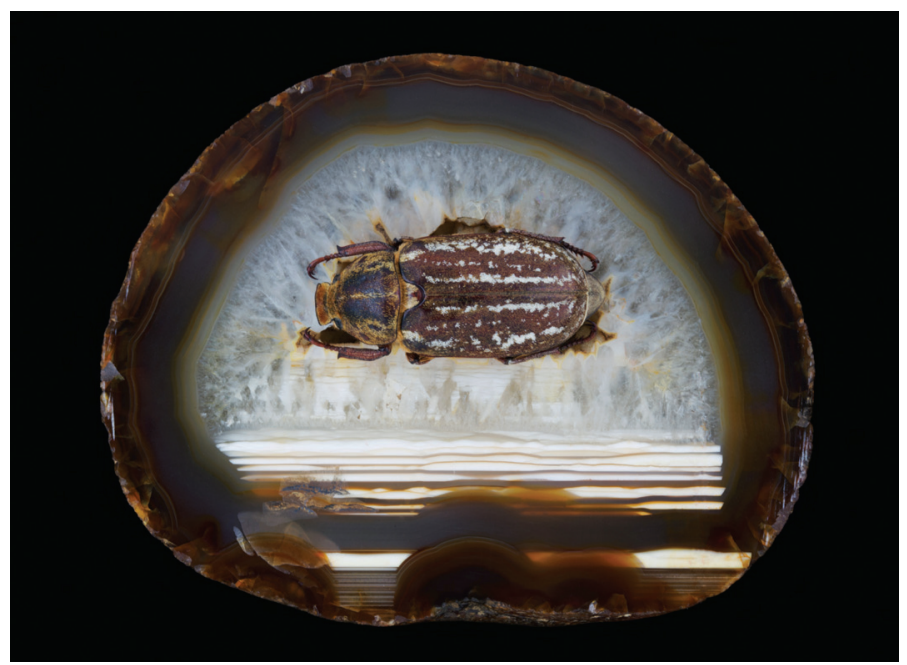

Fig. 5. Anoxia (Protanoxia) orientalis (Krynicky, 1832), Kruševac, Serbia - Quartz, agate, Minais Gerais, Brasil

the authors (Fig. 4). I am sure that the catalogue "Perfection of Evolution - Revelation" will have a special place in every future reader's library, mostly because of its form and its content that are attractive to everyone, regardless of their education, interests and age (Fig. 5). And maybe this very catalogue will inspire some future naturalist... who knows? 